\title{
Sensitivity of Neisseria gonorrhoeae to antibiotics in London (1976-78)
}

\author{
A. D. SETH, B. KOLATOR, AND A. E. WILKINSON \\ From the Venereal Diseases Reference Laboratory (PHLS), London Hospital Research Laboratories, \\ London
}

SUMMARY Three surveys of the sensitivity of pretreatment isolates of gonococci to penicillin, ampicillin, tetracycline, spectinomycin, streptomycin, and co-trimoxazole were carried out during the period 1976-78. Compared with the results of previous surveys in the London area the decline in the proportion of strains of gonococci which are insensitive to penicillin appears to have halted. No changes were found in the levels of resistance to ampicillin, tetracycline, or spectinomycin during the period surveyed, although there was a slight increase in the proportion of strains requiring concentrations of $20 \mu \mathrm{g}$ spectinomycin per $\mathrm{ml}$ for inhibition. Streptomycin resistance has decreased considerably and $91 \%$ of strains are now sensitive to $10 \mu \mathrm{g}$ streptomycin per ml.

\section{Introduction}

The emergence of strains of Neisseria gonorrhoeae in the middle 1950 s which were relatively insensitive to penicillin was rapidly followed by an increase in their prevalence; this trend was more marked in the United States than in the United Kingdom. Martin et al. (1970) found that only $0.6 \%$ of American strains isolated before 1955 had minimum inhibitory concentrations (MICs) greater than $0.03 \mu \mathrm{g} / \mathrm{ml}$; in 1965 this figure had risen to $42 \%$ and between 1968 and 1969 to $65 \%$. In a national survey carried out from 1972 to 1974 on 4405 isolates from 10 major American cities $70 \%$ of the strains had an MIC of $\geqslant 0.06 \mu \mathrm{g} / \mathrm{ml}$, a figure almost identical with that of a previous survey carried out from 1970 to 1971 (Jaffe et al., 1976). Marked differences were found in the proportion of the most resistant strains with an MIC of $20.5 \mu \mathrm{g} / \mathrm{ml}$ in different areas, from $7 \%$ in Des Moines to $26.6 \%$ in Denver; the overall figure for the whole survey was $17 \cdot 4 \%$.

More recently, penicillin resistance among gonococci appears to have shown a marked decline in the United States, from $53.2 \%$ of strains with an MIC of $0.25 \mu \mathrm{g} / \mathrm{ml}$ in 1972 to $29.2 \%$ in 1975 (Reynolds et al., 1976). A similar rise and fall in the proportion of resistant strains has been found in Denmark but resistance is said to have increased during 1976 (World Health Organisation, 1978). The

Address for reprints: Dr A. E. Wilkinson, VD Reference Laboratory, London Hospital, Ashfield Street, London E1 2BL

Received for publication 26 January 1979 appearance of $\beta$-lactamase-producing strains of gonococci early in 1976 (Ashford et al., 1976) suggested that the favourable trend of decreasing resistance of gonococci to penicillin might be halted, but with the exception of the localised outbreak in Liverpool between 1976 and 1977 , which was rapidly contained (Arya et al., 1978), these strains do not appear to have been able to establish themselves in Europe or America.

Although sensitivity studies on nationally collected strains provide an overall picture of patterns of sensitivity, these may not reflect local situations because of geographical variations in sensitivity. This report presents the results of three annual surveys of strains isolated in the East End of London and compares them with previous reports from the London area.

\section{Materials and methods}

The strains studied were isolated from patients attending the Whitechapel Clinic at the London Hospital before any treatment was given. Cultures were made on Oxoid brain heart infusion agar with $10 \%$ horse blood containing $3.0 \mu \mathrm{g} / \mathrm{ml}$ vancomycin and $7.5 \mu \mathrm{g} / \mathrm{ml}$ colistin. Organisms were identified as $N$. gonorrhoeae on the basis of their colonial and microscopical morphology, a positive oxidase reaction, and the production of acid from glucose but not from maltose, lactose, or saccharose. Three surveys were made: June to December 1976 (454 strains), January to March 1977 (225 strains), and May to September 1978 (274 strains). 


\section{SENSITIVITY TESTS}

A plate-dilution method was used in which doubling dilutions of antibiotics were incorporated in brain heart infusion agar with $10 \%$ horse blood. Oxoid diagnostic sensitivity test agar with 5\% lysed horse blood and 1\% Kellogg's defined supplement was used in tests for sensitivity to co-trimoxazole.

Growth from an overnight culture was suspended by a vortex mixer in Oxoid nutrient broth to give an opacity corresponding to a McFarland No. 2 tube and transferred to the series of antibiotic-containing plates and an antibiotic-free control by a multipoint inoculator (Denley Instruments, Billingshurst, Sussex). This gave an inoculum of approximately $10^{4}$ colony-forming units (cfu). Control strains of known sensitivity (IRC 3, IRC 5, obtained from the State Serum Institute, Copenhagen) and the Oxford staphylococcus were included in each set of tests. Plates were incubated for $\mathbf{4 8}$ hours in candle-extinction jars at $36^{\circ} \mathrm{C}$ and the MIC taken as the highest dilution of antibiotic which gave no growth or only a single colony.

\section{Results}

The results of three surveys from 1976 to 1978 of the sensitivity of gonococci to the six antibiotics tested are shown in Tables 1-3 and are compared with earlier surveys from the London area in Table 4. The patterns of sensitivity to tetracycline and streptomycin among the strains which were found to be insensitive to penicillin are shown in Table 5 .

\section{Discussion}

PENICILLIN

In the surveys reported by Rodin and Seth (1972) and Taylor and Seth (1975) the method used was the same as in the present study except that a multipoint inoculator was not used, so that the results are comparable. Differences in the medium, technique, and inoculum size used in the other series (Table 4) allow only a general comparison of results. These show a similar trend to that found in the United States and in Denmark, a rise in the proportion of the most resistant strains (MIC $0.125 \mu \mathrm{g} / \mathrm{ml}$ ) from 1958 to a peak between 1968 and 1970 , followed by a decline until 1976, and a slight increase from this year to 1978. The proportion of strains with an intermediate level of sensitivity $(0.03-0.06 \mathrm{ug} / \mathrm{ml})$ also increased from $19.1 \%$ in 1976 to $25.3 \%$ and $25.6 \%$ in 1977 and 1978 respectively. These may be chance variations and further surveys will be necessary to determine whether the proportion of resistant strains is again increasing.

The appearance of $\beta$-lactamase-producing strains has not significantly affected the position in the area
Table 1 Sensitivity of gonococci to penicillin, ampicillin, tetracycline, and spectinomycin

\begin{tabular}{lcrr}
\hline & \multicolumn{3}{l}{$\%$} \\
\cline { 2 - 4 }$M I C(\mu \mathrm{g} / \mathrm{ml})$ & 1976 & 1977 & 1978 \\
\hline Penicillin & & & \\
$\leqslant 0.004$ & 30.6 & 18.2 & 18.3 \\
0.008 & 25.6 & 27.1 & 27.0 \\
0.015 & 6.4 & 9.8 & 7.3 \\
0.03 & 7.9 & 8.4 & 8.4 \\
0.06 & 11.2 & 16.9 & 17.2 \\
0.125 & 8.6 & 10.2 & 8.0 \\
0.25 & 5.7 & 7.1 & 7.3 \\
$>0.5$ & 4.0 & 2.2 & 6.6 \\
No. of strains tested & 454 & 225 & 274
\end{tabular}

\begin{tabular}{|c|c|c|c|}
\hline $\begin{array}{l}\text { Ampicillin } \\
\leqslant 0.004 \\
0.008 \\
0.015 \\
0.03 \\
0.06 \\
0.125 \\
0.25 \\
>0.5 \\
\text { No. of strains tested }\end{array}$ & $\begin{array}{r}0.4 \\
19 \cdot 2 \\
25 \cdot 0 \\
11 \cdot 6 \\
12 \cdot 5 \\
20 \cdot 1 \\
8 \cdot 9 \\
2 \cdot 2 \\
224\end{array}$ & $\begin{array}{r}0.4 \\
12 \cdot 4 \\
27 \cdot 1 \\
14 \cdot 7 \\
13 \cdot 3 \\
20 \cdot 0 \\
11 \cdot 1 \\
0.9 \\
225\end{array}$ & \\
\hline $\begin{array}{l}\text { Tetracycline } \\
<0.06 \\
0.125 \\
0.25 \\
0.5 \\
1.0 \\
>2.0 \\
\text { No. of strains tested }\end{array}$ & $\begin{array}{r}1 \cdot 1 \\
24 \cdot 7 \\
40 \cdot 1 \\
21 \cdot 6 \\
11 \cdot 5 \\
1 \cdot 1 \\
454\end{array}$ & $\begin{array}{r}1 \cdot 8 \\
22 \cdot 2 \\
40 \cdot 0 \\
23 \cdot 1 \\
12 \cdot 0 \\
0 \cdot 9 \\
225\end{array}$ & $\begin{array}{r}3 \cdot 3 \\
38 \cdot 0 \\
24 \cdot 1 \\
22 \cdot 0 \\
12 \cdot 0 \\
0 \cdot 7 \\
274\end{array}$ \\
\hline $\begin{array}{l}\text { Spectinomycin } \\
<5 \\
10 \\
20 \\
40 \\
\text { No. of strains tested }\end{array}$ & $\begin{array}{c}13 \cdot 7 \\
80 \cdot 4 \\
5 \cdot 9 \\
0 \\
454\end{array}$ & $\begin{array}{r}13 \cdot 3 \\
83 \cdot 1 \\
3 \cdot 6 \\
0 \\
225\end{array}$ & $\begin{array}{c}16 \cdot 1 \\
71 \cdot 9 \\
12 \cdot 0 \\
0 \\
274\end{array}$ \\
\hline
\end{tabular}

Table 2 Sensitivity of gonococci to streptomycin

\begin{tabular}{llllll}
\hline$M I C(\mu \mathrm{g} / \mathrm{ml})$ & & & $\%$ of strains \\
\cline { 3 - 6 } & 500 & & 1976 & 1977 & 1978 \\
\hline S & 50 & S & 76.7 & 83.1 & 90.9 \\
R & S & 5.5 & 1.8 & 0.7 \\
R & R & 17.8 & 15.1 & 8.4 \\
No. of strains tested & 454 & 225 & 274 \\
\hline
\end{tabular}

$\mathbf{S}=$ sensitive; $\mathbf{R}=$ resistant

Table 3 Sensitivity of gonococci to trimethoprimsulphamethoxazole (1978)

\begin{tabular}{llc}
\hline \multicolumn{2}{l}{$M I C(\mu \mathrm{g} / \mathrm{ml})$} & \\
\hline$T M P$ & $S M X$ & \% of strains \\
\hline 0.06 & 1.87 & $2 \cdot 8$ \\
0.125 & 2.375 & 7.9 \\
0.25 & 4.75 & 23.3 \\
0.5 & 9.5 & 36.0 \\
1.0 & 19 & 23.7 \\
2.0 & 38 & 5.9 \\
4.0 & 76 & 0.4 \\
No. of strains tested & 253 \\
\hline
\end{tabular}

TMP = trimethoprim; SMX = sulphamethoxazole 
Table 4 Sensitivity of gonococci to penicillin in the London area (1958-78)

\begin{tabular}{llll}
\hline & \multicolumn{3}{c}{ No. of } \\
Authors & Year & strains tested & \% resistant* \\
\hline Curtis and Wilkinson & 1958 & 302 & $14 \cdot 2$ \\
Cradock-Watson et al. & 1958 & 200 & 10.5 \\
Nicol et al. & 1968 & 91 & 37.4 \\
Leigh et al. & 1969 & 189 & 20.0 \\
Phillips et al. & 1970 & 96 & 35.0 \\
Rodin and Seth & 1972 & 228 & 32.9 \\
Taylor and Seth & 1975 & 277 & 30.0 \\
Phillips et al. & 1976 & 264 & 30.0 \\
Platt & 1976 & 95 & 25.3 \\
Present series & 1976 & 454 & 18.3 \\
& 1977 & 225 & 19.5 \\
& 1978 & 274 & 21.9 \\
\hline
\end{tabular}

*MIC $>0 \cdot 125 \mu \mathrm{g} / \mathrm{ml}$ or $\geqslant 0 \cdot 2$ units $/ \mathrm{ml}$.

Table 5 Percentage of resistance to tetracycline or streptomycin or both among gonococci with diminished sensitivity to penicillin (1976-78)

\begin{tabular}{|c|c|c|c|c|}
\hline \multirow[b]{2}{*}{ Antibiotic } & & \multicolumn{3}{|c|}{$\%$ of strains } \\
\hline & & 1976 & 1977 & 1978 \\
\hline $\begin{array}{l}\text { Penicillin } \\
\text { Tetracycline } \\
\text { Streptomycin }\end{array}$ & $\left.\begin{array}{l}R \\
S \\
S\end{array}\right\}$ & $16 \cdot 9$ & $36 \cdot 4$ & $48 \cdot 3$ \\
\hline $\begin{array}{l}\text { Penicillin } \\
\text { Tetracycline } \\
\text { Streptomycin }\end{array}$ & $\left.\begin{array}{l}\mathbf{R} \\
\mathbf{R} \\
\mathrm{S}\end{array}\right\}$ & $9 \cdot 6$ & $6 \cdot 8$ & $23 \cdot 3$ \\
\hline $\begin{array}{l}\text { Penicillin } \\
\text { Tetracycline } \\
\text { Streptomycin }\end{array}$ & $\left.\begin{array}{l}\mathbf{R} \\
\mathbf{S} \\
\mathbf{R}\end{array}\right\}$ & $44 \cdot 6$ & $38 \cdot 6$ & $10 \cdot 0$ \\
\hline $\begin{array}{l}\text { Penicillin } \\
\text { Tetracycline } \\
\text { Streptomycin }\end{array}$ & $\left.\begin{array}{l}\mathbf{R} \\
\mathbf{R} \\
\mathbf{R}\end{array}\right\}$ & $28 \cdot 9$ & $18 \cdot 2$ & $18 \cdot 3$ \\
\hline No. of strains & & 83 & 44 & 60 \\
\hline
\end{tabular}

Penicilin $\mathrm{R}=\mathrm{MIC} \geqslant 0.125 \mu \mathrm{g} / \mathrm{ml}$; tetracycline $\mathrm{R}=\mathrm{MIC} \geqslant 1 \mu \mathrm{g} / \mathrm{ml}$; streptomycin $\mathrm{R}=\mathrm{MIC} \geqslant 10 \mu \mathrm{g} / \mathrm{ml}$

served by the Whitechapel Clinic. Three such strains were found in 1976, two in 1977, and two in 1978; they formed less than $\mathbf{0 . 2 \%}$ of the gonococci isolated from clinic patient's over the period and were traceable to importations from outside the London area.

\section{AMPICILLIN}

The distribution of sensitivity of gonococci to ampicillin was similar in 1976 and $1977 ; 31.2 \%$ and $32 \%$ of the strains had MICs of $\geqslant 0.125 \mu \mathrm{g} / \mathrm{ml}$ respectively.

\section{TETRACYCLINE}

No changes in the proportion of insensitive strains (MIC $\geqslant 1.0 \mu \mathrm{g} / \mathrm{ml}$ ) were detected during the three surveys: $12.6 \%$ in $1976,12.9 \%$ in 1977 , and $12.7 \%$ in 1978. These insensitive strains tended to show decreased sensitivity to penicillin. In 197825 of 35 strains with an MIC to tetracycline of $\geqslant 1.0 \mu \mathrm{g} / \mathrm{ml}$ had MICs of $\geqslant 0.125 \mu \mathrm{g}$ penicillin $/ \mathrm{ml}$. The proportion of strains with decreased sensitivity to tetracycline is considerably less than the figure of $30 \%$ reported by Phillips et al. (1970).

\section{SPECTINOM YCIN}

No strains resistant to spectinomycin were found during the period surveyed, but the proportion of strains requiring a concentration of $20 \mu \mathrm{g} / \mathrm{ml}$ for inhibition rose slightly to $12 \%$ in 1978 . Two of these 33 strains were also insensitive to penicillin, four to tetracycline, and one to streptomycin. Because of the value of spectinomycin for the treatment of infections with $\beta$-lactamase-producing strains of gonococci, restriction in its use has been recommended to lessen the risk of emergence of spectinomycin-resistant strains. These show highlevel resistance which has been observed to develop during treatment (Reyn et al., 1973). This is evidently a very rare event; Karney et al. (1977) found no evidence of increased resistance when this antibiotic was used as a routine form of treatment for 2938 patients over a period of two years. However, while there are equally effective and cheaper alternatives available for routine treatment, restriction of the use of spectinomycin seems a wise precaution.

\section{STREPTOMYCIN}

The rapid development of high-level resistance to streptomycin led to its abandonment for the treatment of gonorrhoea. Resistance was usually linked to diminished sensitivity to penicillin. In 1970 about a third of the strains had an MIC of $\geqslant 12.5$ $\mu \mathrm{g} / \mathrm{ml}$ (Phillips et al. 1970). The results of the present surveys (Table 2) show that the proportion of streptomycin-resistant strains fell progressively, and in $197890.9 \%$ of the strains were sensitive to a concentration of $10 \mu \mathrm{g} / \mathrm{ml}$. In this period 43 of 60 strains with an MIC of $\geqslant 1 \cdot 125 \mu \mathrm{g}$ penicillin $/ \mathrm{ml}$ were sensitive to $10 \mu \mathrm{g} / \mathrm{ml}$ of streptomycin. A similar fall in resistance to streptomycin has been reported in surveys in Denmark (WHO, 1978).

\section{CO-TRIMOXAZOLE}

Co-trimoxazole was tested only in 1978 (Table 3). There was some correlation between the sensitivity to penicillin and to the trimethoprim-sulphamethoxazole mixture. Thirty-four $(60.7 \%)$ of 56 strains with an MIC of $>0.125 \mu \mathrm{g}$ penicillin $/ \mathrm{ml}$ required $\geqslant 1 \cdot 0 \mu \mathrm{g} / \mathrm{ml}$ trimethoprim plus $19 \mu \mathrm{g} / \mathrm{ml}$ sulphamethoxazole for inhibition compared with $21 \cdot 3 \%$ of $197^{\cdots}$ strains which were sensitive to $\leqslant 0.06 \mu \mathrm{g}$ pencillin $/ \mathrm{ml}$.

\section{MULTIPLE RESISTANCE AMONG PENICILLIN-} INSENSITIVE STRAINS

Gonococci with diminished sensitivity to penicillin often show resistance to other antibiotics such as the 
tetracyclines and streptomycin (Table 5). During the three years covered by the surveys there was a progressive decrease in the proportion of strains which had a multiple resistance, and in 1978 almost half the strains which were insensitive to penicillin were sensitive to both tetracycline and streptomycin.

Gonorrhoea is usually treated on the finding of presumptive gonococci in Gram-stained smears before the results of cultures and sensitivity tests are available. This presupposes a knowledge of the usual patterns of sensitivity of the gonococcal strains in local circulation. The results of these surveys show that, with the exception of the rare $\beta$-lactamaseproducing strains, treatment with penicillin or ampicillin plus probenecid should still give high cure rates in this area. Tetracycline resistance is not common and does not seem to be increasing. Spectinomycin should also be very effective, but its general use is thought to be inadvisable. Further surveys will be needed to see whether the present favourable trend continues.

We wish to thank the World Health Organisation for financial support.

\section{References}

Arya, O. P., Rees, E., Percival, A., Alergant, C. D., Annels, E. H., and Turner, G. C. (1978). Epidemiology and treatment of gonorrhoea caused by penicillinase-producing strains in Liverpool. British Journal of Venereal Diseases. 54, 28-35.

Ashford, W. A., Golash, R. J., and Hemming, V. G. (1976). Penicillinase-producing Neisseria gonorrhoeae. Lancet, 2 , 657-658.
Cradock-Watson, J. E., Shooter, R. A., and Nicol, C. S. (1958). Sensitivity of strains of gonococci to penicillin, sulphathiazole, and streptomycin. British Medical Journal, 1, 1091-1092.

Curtis, F. R. and Wilkinson, A. E. (1958). A comparison of the invitro sensitivity of gonococci to penicillin and the results of treatment. British Journal of Venereal Diseases, 34, 70-82.

Jaffe, H. W. Biddle, J. W. Thornsberry, C. Johnson, R. E., Kaufman, R. E., Reynolds, G. H., Weisner, P. H., and the Cooperative Study Group (1976). National Gonorrhoea Therapy Monitoring Study. In vitro antibiotic susceptibility and its correlation with treatment results. New England Journal of Medicine, 294, 5-9.

Karney, W. W., Pedersen, A. H. B., Nelson, M., Adams, H., Pfeifer, R. T., and Holmes, K. K. (1977). Spectinomycin versus tetracycline for the treatment of gonorrhoea. New England Journal of Medicine, 296, 889-894.

Leigh, D. A., Le Franc, J., and Turnbull, A. R. (1969). Sensitivity to penicillin of Neisseria gonorrhoeae. Relationship to the results of treatment. British Journal of Venereal Diseases, 45, 151-153.

Martin, J. E., Lester, A., Price, E. V., and Schmale, J. D. (1970). Comparative study of gonococcal susceptibility to penicillin in the United States 1955-1969. Journal of Infectious Diseases, 122 459-461.

Phillips, I., Rimmer, D., Ridley, M., Lynn, R., and Warren, C. (1970). In vitro activity of twelve antibiotic agents against Neisseria gonorrhoeae. Lancet, 1, 263-265.

Phillips, I., King, A., Warren, C., and Watts, B. (1976). The activity of penicillin and eight cephalosporins on Neisseria gonorrhoeae. Journal of Antimicrobial Chemotherapy, 2, 31-39.

Reyn, A., Schmidt, H., Trier, M., and Bentzon, M. W. (1973). Spectinomycin hydrochloride (Trobicin) in the treatment of gonorrhoea. Observation of resistant strains of Neisseria gonorrhoeae. British Journal of Venereal Diseases, 49, 54-61.

Reynolds, G. H., Jaffe, H. W., and Thornsberry, C. (1976). Gonococcal resistance to antibiotics. Abstracts of the Annual Meeting of the American Public Health Association. Quoted by P. F. Sparling, Antibiotic resistance in the gonococcus. The Gonococcus, p. 115. Edited by R. B. Roberts, 1977. John Wiley and Sons: New York.

Rodin, P. and Seth, A. D. (1972). Treatment of gonorrhoea with cotrimoxazole, procaine penicillin, and procaine penicillin plus probenecid. British Journal of Venereal Diseases, 48, 517-521.

Taylor, P. K. and Seth, A. D. (1975). Ampicillin plus probenecid compared with procaine penicillin plus probenecid in the treatment of gonorrhoea. British Journal of Venereal Diseases, 51, 183-187.

World Health Organisation (1978). Neisseria gonorrhoeae and gonococcal infections. Technical Reports Series 616, p. 81. World Health Organisation: Geneva. 